\title{
A Systematic Approach to the Integration of EcoDesign Principles into Product Development
}

\author{
Brian Burns - Associate Professor \\ School of Industrial Design, Carleton University, Ottawa \\ brian_burns-eng@carleton.ca
}

\begin{abstract}
In contrast to the principles of Engineering and Design, those of EcoDesign probably only began in earnest following the environmental concerns resulting from the Oil Crisis in the early 1970s. This paper is a reflection of our progress over the years following and offers a Systematic Approach which has evolved through testing over some ten years. The Approach owes much to other such systems and is intended to aid designers and engineers in the task of developing new products in a manner that can be easily integrated into the tried and tested methods already established in Engineering and Design practice.
\end{abstract}

\section{Introduction}

The writings of Rachel Carson[1]concerning the pollution of waterways articulately roused the awareness of many to the potential concerns that have led us to such global responses (with notable exceptions) as the Kyoto Accord. For most of us, the concerns of the global environment first entered our awareness with the Oil Crisis of the early 1970s. Up to that time our global activities had been largely exploitive; we had always been able to move on to 'pastures new' carrying with us the evolving principles of our trades and professions. Engineering and Design have slowly evolved and have been extremely successful in establishing high levels of performance, comfort and safety.

Our knowledge of EcoDesign principles has been developed largely retrospectively. Indeed, the term EcoDesign is of comparatively recent origin, and follows a long line of terms and expressions attempting to help us deal with the extent of the challenges we must face. While we have slowly become aware of such issues as our limited supply of non-renewable resources, and started to adopt improved strategies, our predominant efforts have generally resulted from issues of waste and pollution.

To some extent our response has been passive, 'endof-pipe', aimed mostly to 'band-aid' existing products and processes. This is hardly surprising since the global economies are tightly meshed. To change practices can be costly, and potentially hazardous to the future success of the companies involved. The lack of global standards certainly limited fledgling environmental practices with the potential to increase rather than decrease costs.

Slowly we have started to move our thinking along the 'pipe', but in many instances sustainability and the environment have been seen as costly issues with only a slight advantage to those seen to be adopting socalled 'green' practices.

ISO 9000 and ISO 14000 have done much to help constitute standards, but for the engineer/designer the consequences of their product development and engineering practices are far from predictable at the outset. Considerable work has been undertaken on specific aspects such as, materials usage, energy sources and consumption, and the implications of increasing amounts of waste. In recent years the use of Life Cycle Analysis (LCA) has offered great benefits.

LCA has been based for environmental product review purposes primarily on 3 phases - Manufacture, Use and Discard. With so much appropriate data now available in integrated computer systems, the consequences of the first and last phases, Manufacture and Discard, practices are more readily evaluated. These phases are more easily converted to comparable data. Energy, material, processes, impacts and their costs are thus more quantifiable. However, it is in the central Use Phase that the value of any product is critical, but this is often more difficult to quantify. Simply having data on materials and manufacture and 
so-called 're-cycling' practices does not lend itself to holistic design decision-making at the outset.

The points contained in the systematic approach that follows were all independently determined over a lengthy period of development. During that evolution other similar systems have been acknowledged and considered. The system has been tested over some 10 years mostly with students in Industrial Design programmes undertaking significant design challenges.

Following its use in design projects, the system has been ordered to function in parallel to LCA, but now with 4 dominant phases - Design, Manufacture, Use, and Discard. This has enabled students and practitioners to undertake such evaluation as part of the established Product Development Process.

There are, however, three significant points that have become key to the system, which, for the purpose of this paper are felt worthy of further expansion. These being:

- 'Modes of Obsolescence'

- 'Useness'

- 'Sub-Assembly Based Design’.

\section{Modes of Obsolescence and 'Useness'}

For most readers the term Obsolescence will strike a chord related to its use, predominantly in the USA, as part of 'Planned Obsolescence'. Out of concern for the suppression of new ideas, and to boost an ailing economy came the notion of reducing the useful life of products. This phenomenon was largely a failure, though we are left with it's vestiges. In advertising, for example, we are commonly asked to buy 'This Year's Model'. More recently, in the face of environmental concerns, we have heard the notion of making products last longer - a counter philosophy. The truth, as is common, lies sensibly somewhere in the middle.

Though products have value for many reasons e.g. historic or sentimentality, the predominant value of products lies in function and utility. If a product is a means to an end we cannot simply expect it to last longer. As an example, many slide rules and mechanical calculators have lasted far longer than their social utility demanded with the development of electronic calculators. There are many such examples and many influences of the useful - valuable life of products. If we are to adopt responsible EcoDesign practices it is essential that we optimise the product life phase of all products. Not to minimise, nor to maximise, but to optimise product life in the face of step-by-step evolution, new technological developments, social change etc. It is in the Use Phase that product value is obtained. Benefits in this phase must be balanced against the costs incurred in Manufacture, Use and Discard. As was mentioned earlier, we are currently able to make reasonable decisions in Manufacture and Discard. This research has made considerable progress in the consideration of the factors that will lead to the all important and inevitable obsolescence of a product. These are detailed briefly in the system points that follow.

It is also important to note that while we spend a great deal of effort in the 'Newness' condition of the products we deliver to the customer, it is the 'Useness' condition that will lead to customer respect and an appropriate symbiotic use relationship. The term 'Useness' is invented, and does not wholly revolve around issues of wear-and-tear. Denim jeans are an obvious example of how 'Useness' can become an important part of the successful value relationship with the user. 'Useness' involves many more largely selfevident issues, all connected to encourage the appropriate treatment and survival of a product through to its 'predicted' demise. This issue too is dealt with in the system points.

\section{Sub-Assembly Based Design}

This too is an adapted term, and can easily be recognised in other forms. The intent is to realise the matrix characteristics of all products. Just as wheels are sub-assemblies of vehicles, so too are vehicles subassemblies of transportation and its inherent infrastructure. This work has shown that by considering the product as a sub-assembly of a system and infrastructure(s), and that its components can be considered as related sub-assemblies, qualitative and quantitative decisions can best be made. The traditional bicycle, with its internationally produced array of interchangeable sub-assemblies, is an example of excellent sub-assembly based design. More recent developments in bicycle technology have not displayed similar thinking. As is obvious SubAssembly Based Design is not new, but this research has found the approach both easy to use and, more importantly, to learn. Additionally, Life Cycle Analysis methods currently struggle to appropriately include infra-structural costs.

This 20 Point System offers a means to be aware of such costs, though accurate costing will continue to be difficult. However, the failure of many products has 
been seen, using this system, to be more easily identified with the failure of a sub-assembly.

\section{Considerations for Responsible Design and Manufacture - EcoDesign - A 20 Point Systematic Approach}

The points that follow have been ordered to follow the life cycle planning for any product. Though there are overlaps the points have been grouped to reflect four phases - Design, Manufacture, Use, and Discard.

\section{Design}

- Why do we need it at all? Products are a means to an end - 'we want holes not drills!'

Most products exist because we need something else. We have electric drills because we need easily achieved dimensionally accurate cylindrical holes. Prior to the commencement of any project the right for any new product to exist must be determined. This needs to be more extensively discussed, beyond 'technology push' through to product life and discard implications.

- Respect the history and evolution of existing product systems and cycles, and develop a natural product symbiosis.

While it is easy to merely wish to put a new product in operation, all products exist in an evolved interdependent infrastructure. Changes to such a system may be costly and potentially wasteful even when the new product is an improvement over the existing.

\section{- Respect human understanding and the rhythms, changes, and patterns of life that affect everyone.}

We commonly state that in the face of environmental concerns we should simply make products last longer, yet in many cases the life expectancy and hence the value of the product may well be limited by the user or the use rather than what is technologically possible.

- Optimize principles of 'Product as Service' in the selection of life options - how many toasters or hospitals per hundred years?

Any manufacturer wants loyalty from their customers. To produce a long lasting product may be inappropriate due technological obsolescence (see obsolescence below). Similarly it is wasteful to throw products away because they are no longer sharp, sharpenable, or repairable for example. Better to be a service provider, particularly in the light of potential laws to make manufacturers responsible for their product after the customer is finished with it.

- $\quad$ Respect the inevitable principle of step-by-step product development 'me-too-plus'.

Often a new invention or product direction may be considered groundbreaking or even revolutionary. However, its successful longevity must take into consideration that, other companies may have similar ideas, further improvements might soon be possible, patents may not be completely water-tight, and the market will likely change in response to the initial launch. Each individual product is but a sub-assembly of the natural evolution of the product theme.

- Utilize a strategy of sub-assembly based design as fundamental to a responsible design process.

Every component of a product is part of a matrix that starts with raw materials, leads through components, to products which are part of product systems and social infrastructures. It is vital for the interconnectedness of this chain to be as seamless as possible. Consider and design each sub-assembly optimally and responsibly. 


\section{Manufacture}

- Design for transportation and shipping using local materials wherever possible.

The costs of shipping, particularly in North America are a major component of any product. Shipping of materials on product discard also plays into such costs. There is also likely to be local knowledge of local materials, and how well they perform in known environments. Most socalled global manufacturers e.g. Japanese auto companies, ultimately manufacture in the country of sale.

- Use the least number and volume of materials (by weight and energy) preferably non-toxic, nonhazardous, renewable, natural resources, and already in the 'system' - Close all loops.

This is a simple objective, but a difficult proposition. Current 'Eco' data makes choices of raw material, energy and reprocessing possible. The increased pressure and legislation on companies to be responsible for their products after the customer has no longer use for them, makes this point more significant. Disassembly and value retention is also far easier with minimal numbers of identifiable materials. It is also clear that any reduction in the transportation of excess weight, in manufacture, use, and discard, will offer worthwhile savings.

- Manufacture should respect the health of human labour.

A substantial part of manufacturing costs is attributable to human labour. The health of such workers is regulated in many instances, but the objective of sustainability is not simply aimed at the global environment, it is also responsible for the sustainability of us as part of the workforce.

\section{Manufacture \& Use}

- Adopt consumption rates that match global balance and regional/local equilibrium.

This is self-evident now that the finite nature of our planet is better understood.
As a simple maxim for designing - a product made of wood should last at least as long as it took the tree to grow the wood in the first place.

- Adopt strategies for upgrade, refill, and remanufacture wherever possible.

As a continuance of the notion of step-bystep development, as some software has shown us, products can be upgraded during their useful life. This concept can be designed in at the outset. Recharging batteries and sharpening blades are simple examples. Here too the prudent consideration for the sub-assemblies plays an important role.

Use

- Minimize (optimize) the energy used and waste created by the product in its lifetime.

Many products such as automobiles and digital display telephones have a greater environmental impact during the use phase than in manufacture and discard. Choices made when designing can have a positive impact.

- Work with the forces of nature (gravity, Newton's laws etc.) - why do we need aerosols?

While it is tempting to promote labour saving devices, in many cases the inconvenience of the labour involved e.g. shaving cream aerosol products, is minor but the environmental impacts are considerable.

- Use appropriate levels of technology to optimize reliability and communication of function.

Reliability decreases exponentially with the increase in connected components. Similarly electronic monitoring of operation raises considerably the number of components and decreases the ease of failure diagnosis. We continue to chase the opportunities offered by new technologies, but all too easily move away from the appropriate intermediate technologies. The user understanding of the traditional bicycle is far superior to the 
comprehension offered by the modern automobile.

\section{- Optimize the wear-and-tear (useness) characteristics of the product.}

The automobile and the everyday shoe are two products that we buy bright and shiny' and expose to the worst conditions. All products offer a degree of ownership and demand a relationship with a user/maintainer. Promoting an appropriate symbiotic relationship with the user/maintainer can do much to enhance the longevity of the product - optimising product value.

- Respect the four modes of obsolescence (aesthetic, social, technological, uneconomical repair).

The mode of obsolescence of a product is to a large extent predictable. The four modes listed above, usually work in combination, but should be respected individually. Briefly: Aesthetic obsolescence can be as a result of a change in fashion or as a result of unsatisfactory wear-and -tear; Social obsolescence may be as a result of a change in legislation or a change in social habit; Technological obsolescence is often the result of newer technologies making the task easier or better; Uneconomical repair is an increasingly common form of obsolescence particularly in electronic goods with a relatively high labour involvement and fast changing product evolution. A simple example of an unsatisfactory combination is common when long life mature products are discarded due to aesthetic obsolescence - avocado green refrigerators!

- Repair and maintenance should be clear and, whenever possible, undertaken by the user - without drudgery or risk of injury.

Repair call-outs are costly and often embarrassing when the cure is simply a new fuse or a misunderstood diagram. Within limits, tinkering (a lost art of engineers?) offers means for the user to appropriately and safely work with the product. The removal of such an interaction may well prove costly.

\section{Use \& Discard}

- Employ options of disassembly, breakdown, upgrade, reprocessing, disposal, value and material identification.

A great deal of new work is available concerned with design for disassembly. This is valuable when used in conjunction with consideration of the next life of the components and the raw materials. One without due consideration for the other is potentially wasteful. Appropriate consideration of the sub-assemblies in all cases can be advantageous.

\section{Discard}

- Minimize landfill to natural 'nonconcentrated' materials that will yield predictable results.

Waste is a measure of failure. Toxic waste continues to have impact long after disposal has been undertaken. There is no such place as 'Away'. The advantages of high-performance composite material are attractive in many applications. All too often, however, such materials are hard to dispose of responsibly. The term recycle is much overused, with most materials being downgraded or 'down-cycled' on discard. All materials should have reprocessing - a preferred term - options understood in advance of manufacture not at 'the end-of-the-pipe'.

- The next life options of the product and its materials (reprocessing and manufacture) should be known before manufacture.

As we move our thinking back to dealing with environmental impact in design, it will become increasingly economically beneficial to make such optimising decisions before manufacture. 


\section{Endnote}

This Systematic Approach has been used in the design of products ranging from appliances to buses, and from medical equipment to seating. In the majority of cases this has been for graduating students in Industrial Design, and in all cases the implications have been reasonably well understood. Its use in Design Engineering, having a greater regard for functionality should be easier to model. In all cases the ideal cannot expect to produce a perfect solution. The intent is to help initiate a workable approach to product development rather than as an extra costly step in the already complex process. Thus the system can generally best be utilised by those able to design; this is not a substitute. No doubt these 20 points will evolve further in the near future, hopefully to their own ultimate obsolescence, when EcoDesign will become just one of the evolutionarily developed considerations in Engineering, Design and Engineering Design.

\section{References}

[1] Rachel Carson, "The Sea Around Us" and "Silent Spring", Oxford University Press, New York, 1951 and 1952.

[2] Dr Conrad Luttrop, "Ten Golden Rules in EcoDesign", Tools for Sustainable Product Design and Development, Stockholm, Sweden, 2004 